Article

\title{
Improving the Thermoelectric Properties of the Half-Heusler Compound VCoSb by Vanadium Vacancy
}

\author{
Lihong Huang ${ }^{1,2}{ }^{1,}$, Junchen Wang ${ }^{1}$, Xiaobo Mo ${ }^{1}$, Xiaobo Lei ${ }^{1}$, Sude Ma ${ }^{1}$, Chao Wang ${ }^{2, *}$ and \\ Qinyong Zhang ${ }^{1, *}$ \\ 1 Key Laboratory of Fluid and Power Machinery of Ministry of Education, School of Materials Science \& \\ Engineering, Xihua University, Chengdu 610039, China; huang.lihong@foxmail.com (L.H.); \\ wangjunchen94@163.com (J.W.); moxiaobo77@163.com (X.M.); leixiaoboxhu@163.com (X.L.); \\ masude2007@163.com (S.M.) \\ 2 Clean Energy Materials and Engineering Center, School of Electronic Science and Engineering, State Key \\ Laboratory of Electronic Thin Film and Integrated Devices, University of Electronic Science and Technology \\ of China, Chengdu 610054, China \\ * Correspondence: cwang@uestc.edu.cn (C.W.); bohr123@163.com (Q.Z.)
}

Received: 18 March 2019; Accepted: 16 May 2019; Published: 20 May 2019

\begin{abstract}
The effects of $\mathrm{V}$ vacancy on the thermoelectric performance of the half-Heusler compound VCoSb have been investigated in this study. A certain amount of CoSb secondary phase is generated in the VCoSb matrix when the content of $\mathrm{V}$ vacancy is more than $0.1 \mathrm{at} \%$. According to the results, a ZT value of 0.6 , together with a power factor of $29 \mu \mathrm{W} \mathrm{cm}{ }^{-1} \mathrm{~K}^{-2}$ at $873 \mathrm{~K}$, were achieved for the nonstoichiometric sample $\mathrm{V}_{0.9} \mathrm{CoSb}$. This proved that moderate $\mathrm{V}$ vacancy could improve the thermoelectric (TE) properties of VCoSb. The noticeable improvements are mainly owing to the incremental Seebeck coefficient, which may benefit from the optimized carrier concentration. However, too much $\mathrm{V}$ vacancy will result in more CoSb impurity and deteriorate the TE performances of VCoSb owing to the increased thermal conductivity.
\end{abstract}

Keywords: Half-Heusler; VCoSb; vacancy; nonstoichiometry; thermoelectric

\section{Introduction}

Thermoelectric (TE) materials are a type of functional material that can be used to directly convert thermal energy into electrical energy through the motion of internal carriers in solids. The conversion efficiency of TE materials is characterized by the dimensionless figure of merit $Z T=S^{2} \sigma T /\left(\kappa_{\mathrm{e}}+\kappa_{L}\right)$, where $S$ is the Seebeck coefficient, $\sigma$ is the electrical conductivity, $T$ is the absolute temperature, and $\kappa_{\mathrm{e}}$ and $\kappa_{L}$ are the electronic and lattice contributions to the total thermal conductivity $\kappa$, respectively [1]. Particularly, the above three TE parameters $(S, \sigma$, and $\kappa)$ are correlated with each other by carrier concentration. An effective way to enhance $Z T$ is by optimizing carrier concentration.

According to the definition of $Z T$, there are two strategies for ZT enhancement: One strategy is increasing the TE power factor $\left(S^{2} \sigma\right)$ via band engineering, for example, modifying electron states by resonant levels [2], energy band convergency [3], low band effective mass [4], or weakening the carrier scattering [5]. The other strategy is to reduce $\kappa_{L}$, e.g., alloying to induce point defects [6], increasing phonon scattering with nanostructure [7], or using materials with strong anharmonicity [8] and low sound velocity [9].

Over the last few decades, half-Heusler $(\mathrm{HH})$ compounds, a type of thermoelectric material, have been given a lot of attention for their desirable characteristics, such as excellent mechanical robustness, good TE performance, high-temperature stability, and low toxicity, all of which are of great 
significance for TE materials' practical applications [10-12]. The properties of HH compounds are strongly influenced by the number of valence electrons in a unit cell; $\mathrm{HH}$ compounds with a number of 18 valence electrons are typically semiconductors, and $\mathrm{M}_{\mathrm{I}} \mathrm{NiSn}, \mathrm{M}_{\mathrm{I}} \mathrm{CoSb}\left(\mathrm{M}_{\mathrm{I}}=\mathrm{Ti}, \mathrm{Zr}, \mathrm{Hf}\right), \mathrm{M}_{\mathrm{II}} \mathrm{FeSb}$ $\left(\mathrm{M}_{\mathrm{II}}=\mathrm{Nb}, \mathrm{V}\right)$, and their alloys have been extensively investigated as promising TE materials applicated at medium-high temperature [13-22].

Unconventionally, experiments have confirmed that $\mathrm{NbCoSb}$ and $\mathrm{VCoSb}$, with a cubic $\mathrm{HH}$ structure and 19 valence electrons per unit cell, exhibit moderate n-type TE properties and achieve a $Z T$ value of about 0.4 and 0.5 at $973 \mathrm{~K}[23,24]$. However, impurity phases always exist in a $\mathrm{NbCoSb}$ system and obstruct the improvement of its TE properties [25-27]. Moreover, Zeier et al. presented that $\mathrm{NbCoSb}$ with stoichiometric composition is unstable, and the nonstoichiometric $\mathrm{HH}$ compound $\mathrm{Nb}_{0.8} \mathrm{CoSb}$ with 18-electron and $\mathrm{Nb}$ vacancies was pointed out to be a more stable semiconductor [28]. More recently, $\mathrm{Zhu}$ et al. confirmed experimentally that $\mathrm{Nb}_{0.8} \mathrm{CoSb}$ is a stable $\mathrm{HH}$ compound, and the carrier concentration can be improved by the content of $\mathrm{Nb}$ vacancy. A peak ZT of about 0.9 at $1123 \mathrm{~K}$ was achieved for $\mathrm{Nb}_{0.83} \mathrm{CoSb}$ [29].

In this work, we focus on another HH compound, the thermoelectric material VCoSb with nominal $\mathrm{VEC}=19$ (VEC is the valence electron count per unit cell). Inspired by previous research on $\mathrm{NbCoSb}$, we have synthesized $\mathrm{V}_{1-x} \mathrm{CoSb}$ compounds with different contents of $\mathrm{V}$ vacancies $(x=0,0.05,0.1$, $0.15,0.2$, and 0.25 ), and investigated the effects of $\mathrm{V}$ vacancy on the TE properties. According to our experiment results, too much $\mathrm{V}$ vacancy will generate more impurity phase ( $\mathrm{CoSb}$ ), leading to a reduction in the TE performance. It is noteworthy that a certain amount of V vacancy in VCoSb will enhance the power factor and increase $Z T$ of $\mathrm{VCoSb}$. A peak $Z T$ value of about 0.6 was achieved for $\mathrm{V}_{0.9} \mathrm{CoSb}$ at $973 \mathrm{~K}$. The present work again demonstrates that nonstoichiometric 19-valence electron HH compounds are hopeful TE materials.

\section{Experimental Details}

A series of $\mathrm{V}_{1-x} \mathrm{CoSb}$ samples with different contents of $\mathrm{V}$ vacancies $(x=0,0.05,0.1,0.15,0.2$, and 0.25 ) were synthesized by powder sintering, ball milling, and hot pressing. The raw powder materials were loaded into a stainless-steel jar, mixed for $0.5 \mathrm{~h}$ without grinding balls, and then consolidated into disks by cold pressing at room temperature for $20 \mathrm{~min}$. The pre-compression disks were sealed in a quartz tube, sintered at $1073 \mathrm{~K}$ for $18 \mathrm{~h}$, and then air cooled to room temperature. The sintered disks were sealed inside a jar in a glove box with argon gas protection, and then ball milled for $5 \mathrm{~h}$ by a high-energy SPEX 8000M Mixer/Mill (SPEX Sample Prep., Metuchen, NJ, USA) to yield the powder. The obtained powder was transferred and loaded into a graphite die, then hot-pressed at $1023 \mathrm{~K}$ for 2 min under $75 \mathrm{MPa}$ by a direct current hot press to obtain a disk sample. The dense samples obtained were about $12.7 \mathrm{~mm}$ in diameter and $2 \mathrm{~mm}$ in thickness.

The thermal conductivity $\kappa=d D C_{\mathrm{p}}$ was calculated using the measured density $(d)$ using the Archimedes method, thermal diffusivity (D) using the laser flash method (LFA 457, Netzsch, Selb, Germany), and specific heat capacity (Cp) using differential scanning calorimetry (DSC 404 C, Netzsch, Selb, Germany). Bar-shaped samples of about $2 \mathrm{~mm} \times 2 \mathrm{~mm} \times 11 \mathrm{~mm}$ were used for measuring the electrical conductivity and Seebeck coefficient simultaneously from 300 to 973 K (ZEM-3, ULVAC Riko, Chigasaki, Japan).

The phase characterizations were measured by X-ray diffraction (XRD, D2 PHASER, Bruker, Billerica, MA, USA) with $\mathrm{Cu} \mathrm{K} \mathrm{K}_{\alpha}$ radiation. The microstructures were observed using a field emission scanning electron microscope (FESEM, QUANTA 250, FEI, Hillsboro, OR, USA).

\section{Results and Discussion}

Figure 1 shows the $\mathrm{XRD}$ patterns of the $\mathrm{V}_{1-x} \operatorname{CoSb}(x=0-0.25)$ samples. As we can see, the main phase is the $\mathrm{HH}$ phase of the $\mathrm{VCoSb}$ with a cubic MgAgAs-type crystal structure. Although extremely weak impurity peaks of $\mathrm{CoSb}$ phase can be found in the $\mathrm{V}_{0.9} \mathrm{CoSb}$ sample, the stoichiometric $\mathrm{VCoSb}$ sample and the nonstoichiometric $\mathrm{V}_{0.95} \mathrm{CoSb}$ sample were found to be pure in phase. Obvious peaks of 
impurity phase of CoSb are observed when the content of $\mathrm{V}$ vacancy is more than 0.1 , and the amount of the impurity phase of $\mathrm{CoSb}$ increases with the increasing content of $\mathrm{V}$ vacancy. Although there is a certain amount of $\mathrm{V}$ vacancies in our samples, the cubic $\mathrm{HH}$ phase crystal structure still remains.

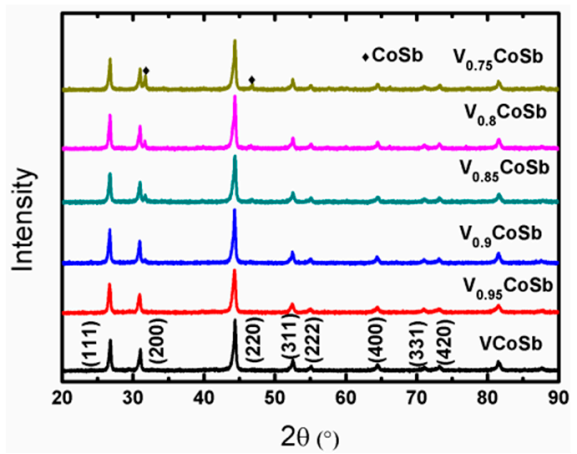

Figure 1. X-ray diffraction (XRD) patterns of $\mathrm{V}_{1-x} \mathrm{CoSb}$ samples.

The lattice parameter, and the theoretical, experimental, and relative densities of the $\mathrm{V}_{1-x} \mathrm{CoSb}$ samples are shown in Table 1 . The lattice parameter changes only slightly upon the increasing $\mathrm{V}$ vacancies, indicating no significant change in the main phase structure; which is in agreement with the results of the XRD patterns. The theoretical density is calculated by $d_{\text {cal }}=\sum n_{\mathrm{i}} \mathrm{M}_{\mathrm{i}} /\left(a^{3} N_{A}\right)$, where $n_{\mathrm{i}}$ is the number of atoms of $\mathrm{V}, \mathrm{Co}$, and $\mathrm{Sb}$ per unit cell, $\mathrm{M}_{\mathrm{i}}$ is the corresponding atomic mass of each element, $a$ is the lattice constant, and $N_{A}$ is the Avogadro constant $\left(6.023 \times 10^{23} \mathrm{~mol}^{-1}\right)$. The relative densities of all of the hot-pressed samples were more than $93 \%$.

Table 1. Lattice parameter and theoretical, experimental, and relative density of $\mathrm{V}_{1-x} \mathrm{CoSb}(x=0,0.05$, $0.1,0.15,0.2$, and 0.25 ) samples.

\begin{tabular}{ccccc}
\hline \multirow{2}{*}{ Nominal Composition } & \multirow{2}{*}{ Lattice Parameter $(\mathbf{n m})$} & \multicolumn{2}{c}{ Density $\mathbf{( g / \mathbf { c m } ^ { 3 } )}$} & \multirow{2}{*}{ Relative Density $(\mathbf{\%})$} \\
\cline { 3 - 4 } & & Theoretical & Experimental & \\
\hline $\mathrm{VCoSb}$ & 0.5772 & 7.45 & 8.01 & 93.01 \\
$\mathrm{~V}_{0.95} \mathrm{CoSb}$ & 0.5772 & 7.53 & 7.87 & 95.67 \\
$\mathrm{~V}_{0.9} \mathrm{CoSb}$ & 0.5771 & 7.6 & 7.79 & 97.56 \\
$\mathrm{~V}_{0.85} \mathrm{CoSb}$ & 0.5770 & 7.62 & 7.73 & 98.57 \\
$\mathrm{~V}_{0.8} \mathrm{CoSb}$ & 0.5770 & 7.63 & 7.68 & 99.35 \\
$\mathrm{~V}_{0.75} \mathrm{CoSb}$ & 0.5769 & 7.64 & 7.66 & 99.74 \\
\hline
\end{tabular}

As shown in Figure 2a, the scanning electron microscope (SEM) image of the fracture surface of $\mathrm{V}_{0.9} \mathrm{CoSb}$ sample indicates dense and compact hot-pressed bulk samples, and the grainsize of the sample is in a range from hundreds of nanometers to one micrometer. The back-scattering electron (BSE) image of $\mathrm{V}_{0.9} \mathrm{CoSb}$ in Figure $2 \mathrm{~b}$ shows no apparent phase segregation, meaning very little secondary phase in the $\mathrm{V}_{0.9} \mathrm{CoSb}$ sample.
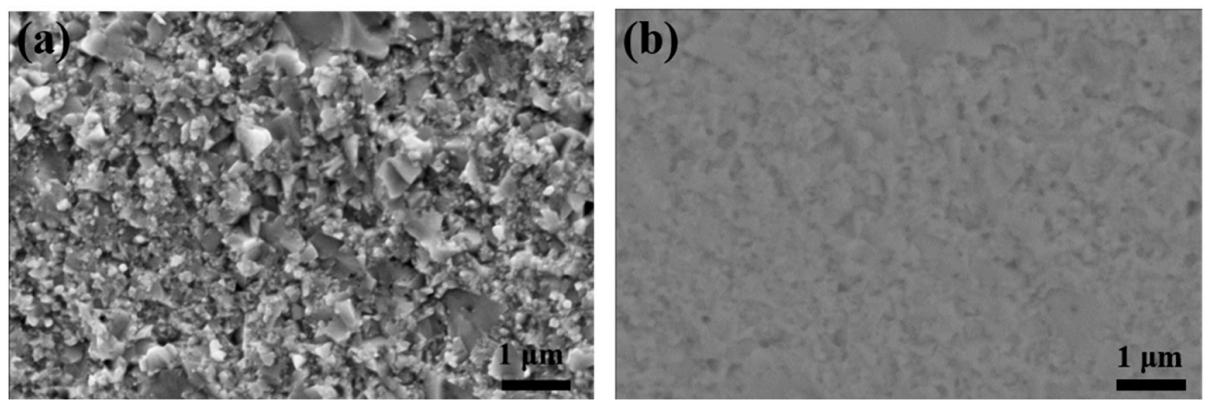

Figure 2. Scanning electron microscope (SEM) image (a) and back-scattering electron (BSE) image (b) of the hot-pressed sample $\mathrm{V}_{0.9} \mathrm{CoSb}$. 
The temperature-dependent thermal properties are shown in Figure 3. Due to the limitation of our thermal performance tester system, the maximum test temperature was $873 \mathrm{~K}$, which is lower than the maximum electrical test temperature of $973 \mathrm{~K}$. As shown in Figure 3a, the thermal diffusivity $D$ monotonically decreased over the whole measured temperature range. Additionally, the thermal diffusivity clearly increased when the $\mathrm{V}$ vacancy content is more than 0.15 , which may be due to the increasing amount of CoSb secondary phase in the sample. As shown in Figure $3 b$, the larger the amount of $\mathrm{CoSb}$, the higher the thermal capacity $C_{p}$. Figure $3 \mathrm{c}$ shows the total thermal conductivity $\kappa_{\text {total }}$ for $\mathrm{V}_{1-x} \mathrm{CoSb}$ samples as the temperature changes. $\kappa_{\text {total }}$ of $\mathrm{V}_{0.9} \mathrm{CoSb}$ decreased with increasing temperature from $3.84 \mathrm{~W} \mathrm{~m}^{-1} \mathrm{~K}^{-1}$ at $300 \mathrm{~K}$ to $3.58 \mathrm{~W} \mathrm{~m}^{-1} \mathrm{~K}^{-1}$ at $873 \mathrm{~K}$, almost close to that of VCoSb. Typically, the total thermal conductivity contains two parts, the electronic thermal conductivity and the lattice thermal conductivity, namely, $\kappa_{\text {total }}=\kappa_{e}+\kappa_{L}$. The electronic thermal conductivity $\kappa_{e}$ can be estimated by the Wiedemann-Franz relation, $\kappa_{e}=L \sigma T$, where $L$ is the Lorentz number. Usually, the Lorentz number is between two limiting values. For metals and highly degenerate semiconductors, it is $2.45 \times 10^{-8} \Omega \mathrm{W} \mathrm{K}^{-2}$, whereas, for a non-degenerate semiconductor, it is $1.49 \times 10^{-8} \Omega \mathrm{W} \mathrm{K}^{-2}$. Herein, the Lorentz number is estimated by fitting the measured Seebeck coefficient using a single parabolic band (SPB) model, as shown in Figure S1, assuming the acoustic phonon scattering mechanism and Equations (1)-(3) are valid, instead of using a constant value of $2.45 \times 10^{-8} \Omega \mathrm{W} \mathrm{K}^{-2}$ [30].

$$
\begin{gathered}
S= \pm \frac{k_{B}}{e}\left(\frac{(r+5 / 2) F_{r+3 / 2}(\eta)}{(r+3 / 2) F_{r+1 / 2}(\eta)}-\eta\right) \\
F_{\mathrm{n}}(\eta)=\int_{0}^{\infty} \frac{x^{n}}{1+e^{x-\eta}} d x \\
L=\left(\frac{k_{B}}{e}\right)^{2}\left[\frac{(r+7 / 2) F_{r+5 / 2}(\eta)}{(r+3 / 2) F_{r+1 / 2}(\eta)}-\left(\frac{(r+5 / 2) F_{r+3 / 2}(\eta)}{(r+3 / 2) F_{r+1 / 2}(\eta)}\right)^{2}\right]
\end{gathered}
$$

where $F_{n}(\eta)$ is the $n$th order Fermi integral, $\eta$ is the reduced Fermi energy, $r$ is the scattering factor, $h$ is Plank's constant, $k_{\mathrm{B}}$ is Boltzmann's constant, $x$ is the variable of integration, and $e$ is the electron charge.

The obtained $\kappa_{L}$ and $\kappa_{e}$ are plotted in Figure $3 \mathrm{~d} . \kappa_{L}$ exhibits significant enhancement with increasing $\mathrm{V}$ vacancy, i.e., increasing amounts of $\mathrm{CoSb}$ impurity. For example, $\kappa_{L}$ at room temperature increased from $2.32 \mathrm{~W} \mathrm{~m}^{-1} \mathrm{~K}^{-1}$ for the $\mathrm{V}_{0.95} \mathrm{CoSb}$ sample to $3.41 \mathrm{~W} \mathrm{~m}^{-1} \mathrm{~K}^{-1}$ for the $\mathrm{V}_{0.8} \mathrm{CoSb}$ sample. As shown in the inset of Figure $3 \mathrm{~d}, \kappa_{e}$ of $\mathrm{VCoSb}$ showed an increasing trend over the whole temperature range; however, it decreased with the increasing temperature for V-deficient samples $\mathrm{V}_{1-x} \mathrm{CoSb}$ $(x>0)$. Furthermore, $\kappa_{e}$ at room temperature distinctly increased from $1.75 \mathrm{~W} \mathrm{~m}^{-1} \mathrm{~K}^{-1}$ for VCoSb to $2.64 \mathrm{~W} \mathrm{~m}^{-1} \mathrm{~K}^{-1}$ for $\mathrm{V}_{0.75} \mathrm{CoSb}$ upon the increasing $\mathrm{V}$ vacancy content, which can be ascribed to the high electrical conductivity of the CoSb impurity.

Figure $4 \mathrm{a}$ shows the temperature dependence of electrical conductivity of the $\mathrm{V}_{1-x} \mathrm{CoSb}$ samples. The electrical conductivity decreased at the beginning with the increasing temperature due to the strong electron scattering, displaying metal or degenerate semiconductor transport behavior. However, after $873 \mathrm{~K}$ the electrical conductivity started to increase, which may be due to the intrinsic carrier thermal excitation. We calculated the temperature-dependence-exponent of the conductivity $\left(\sigma \mathrm{vs} . T^{\alpha}\right)$ before thermal excitation and found that the carrier scattering mechanism may change after inducing $\mathrm{V}$ vacancy. The conductivity of VCoSb showed a temperature exponent of -0.65 (green dotted line), indicative of alloy and phonon scattering of the carriers, although alloy scattering is stronger. However, the temperature exponent of -0.9 for $\mathrm{V}_{0.9} \mathrm{CoSb}$ (blue dotted line) and -0.93 for $\mathrm{V}_{0.75} \mathrm{CoSb}$ (red dotted line) implies that phonon scattering has a stronger effect ( $\sigma$ vs. $T^{-0.5}$ for alloying scattering and $\sigma$ vs. $T^{-1.5}$ for acoustic phonon scattering) [31,32]. 

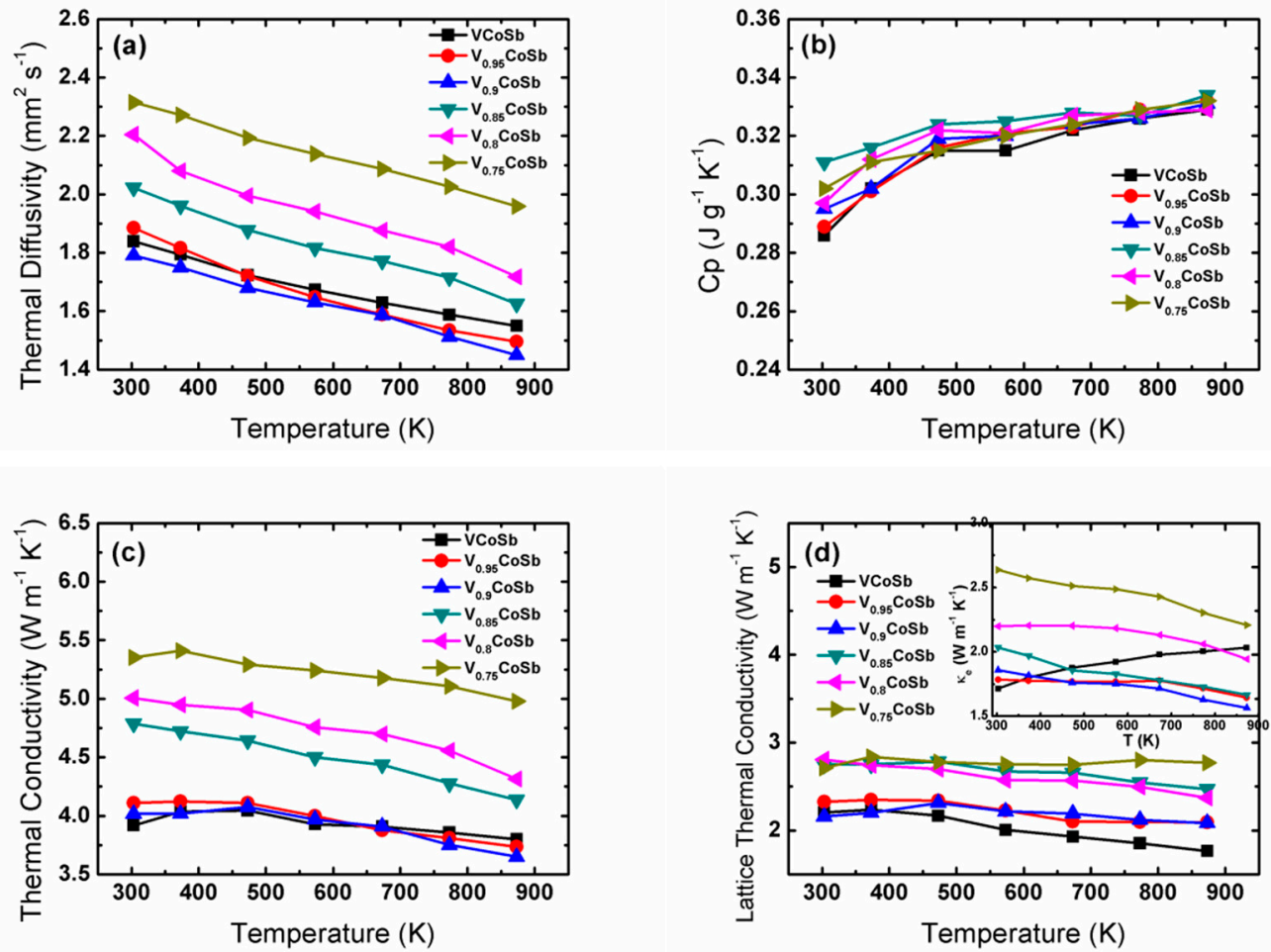

Figure 3. Temperature-dependent thermal diffusivity (a), thermal capacity (b), total thermal conductivity (c), and lattice and electronic thermal conductivity (d) of $\mathrm{V}_{1-x} \mathrm{CoSb}$.
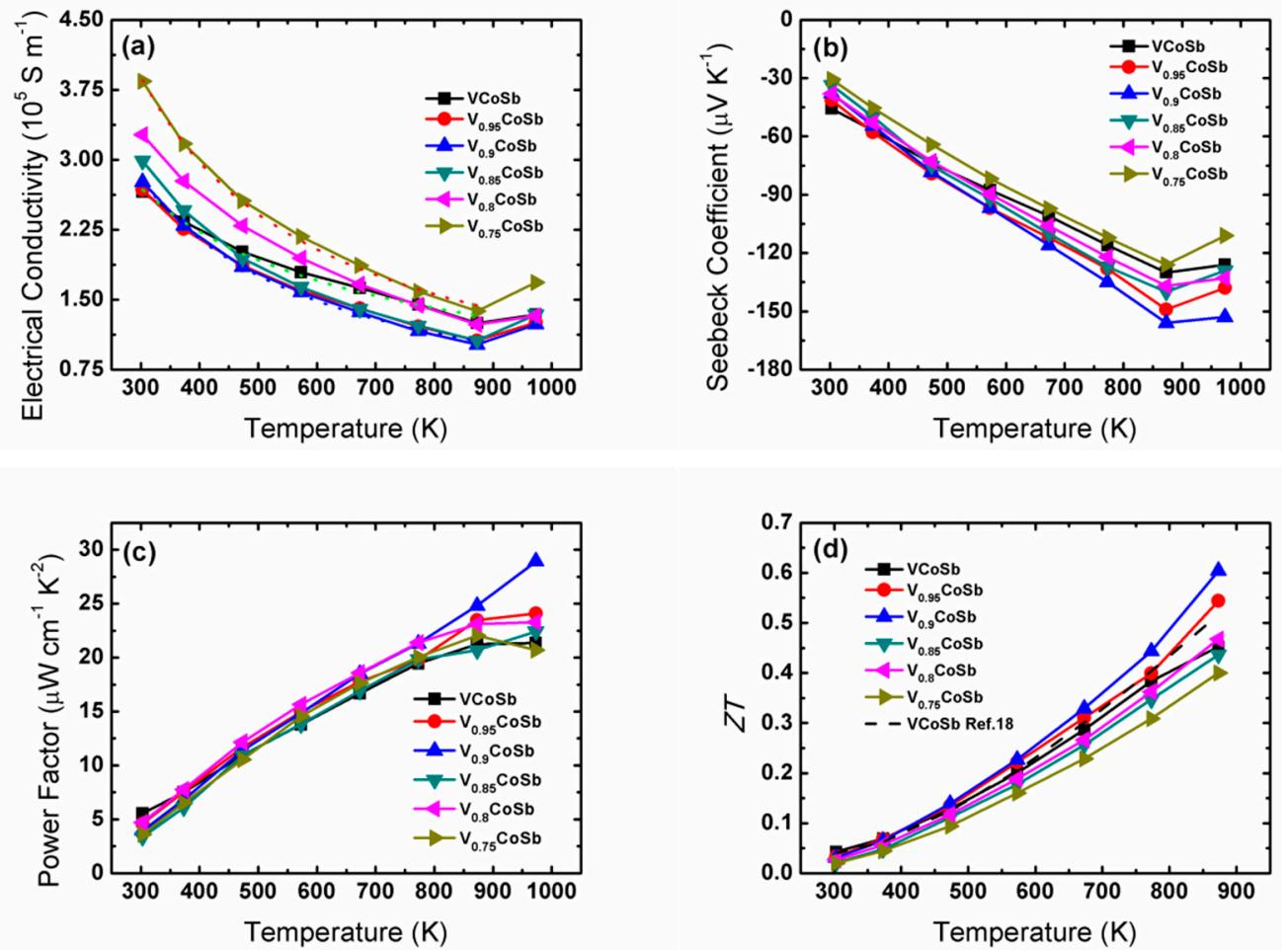

Figure 4. Temperature-dependent electrical conductivity (a), Seebeck coefficient (b), power factor (c), and $\mathrm{ZT}(\mathbf{d})$ of $\mathrm{V}_{1-x} \mathrm{CoSb}$.

We also prepared pure phase $\mathrm{CoSb}$, and characterized its electrical properties, as shown in Figure S2. The bulk CoSb sample had a density of $8.63 \mathrm{~g} / \mathrm{cm}^{3}$, and a room temperature conductivity of $37.5 \times 10^{5} \mathrm{~S} / \mathrm{m}$. Based on its conductivity dependence on temperature $\left(\sigma\right.$ vs. $\left.T^{-1.5}\right)$, which implies that 
acoustic phonon scattering is predominant during the carrier transport, the carrier concentration here is considered to be nearly temperature-irrelevant due to the metallic nature of carriers. Therefore, too much CoSb impurity in the matrix will degrade the TE performance of VCoSb, compared with other secondary phases, such as $\mathrm{ZnO}$ and $\mathrm{SiC}[33,34]$. CoSb is not a suitable scattering phase because of its strong metallic properties.

As shown in Figure $4 b$, the negative Seebeck coefficients indicate an n-type transport behavior of our samples. Moreover, the Seebeck coefficient enhanced with the increase of temperature before $873 \mathrm{~K}$ and then decreases on account of intrinsic thermal excitation. The Seebeck coefficient for the $\mathrm{V}$ vacancy samples is larger than that of $\mathrm{VCoSb}$, except for $\mathrm{V}_{0.75} \mathrm{CoSb}$. The $\mathrm{V}_{0.9} \mathrm{CoSb}$ sample has the highest peak Seebeck coefficient of $-153 \mu \mathrm{V} / \mathrm{K}$ at $873 \mathrm{~K}$, which should benefit from the improved carrier concentration.

Consequently, the power factor $\left(S^{2} \sigma\right)$ increased during the whole temperature range and the $\mathrm{V}_{0.9}$ CoSb sample had an improved peak value of $29 \mu \mathrm{W} \mathrm{cm}{ }^{-1} \mathrm{~K}^{-2}$; greater than $\operatorname{VCoSb}\left(21 \mu \mathrm{W} \mathrm{cm}{ }^{-1} \mathrm{~K}^{-2}\right)$ at $973 \mathrm{~K}$ (Figure 4c). Finally, the $\mathrm{ZT}$ values are presented in Figure $4 \mathrm{~d}$. It is apparent that the $\mathrm{V}_{0.9} \mathrm{CoSb}$ sample showed the highest ZT of 0.6 at $873 \mathrm{~K}$, nearly a $25 \%$ enhancement compared to $\mathrm{VCoSb}$, on account of the improved Seebeck coefficient and power factor.

\section{Conclusion}

A set of $\mathrm{V}$ vacancy $\mathrm{V}_{1-x} \mathrm{CoSb}$ samples $(x=0,0.05,0.1,0.15,0.2$, and 0.25$)$ were prepared by powder sintering, ball milling, and hot pressing. The influences of $\mathrm{V}$ vacancy on the thermoelectric properties of the $\mathrm{HH}$ compound $\mathrm{VCoSb}$ were studied. A certain amount of CoSb secondary phase was generated in the $\mathrm{VCoSb}$ matrix when $\mathrm{x}$ was more than 0.1 . Too much $\mathrm{V}$ vacancy yields more $\mathrm{CoSb}$ impurity, and deteriorated the TE performance, owing to the increased thermal conductivity; while moderate $\mathrm{V}$ vacancy could improve the TE property, which may benefit from the optimized carrier concentration. Finally, a maximum ZT of about 0.6 was obtained at $873 \mathrm{~K}$ for $\mathrm{V}_{0.9} \mathrm{CoSb}$, mainly because of the increased Seebeck coefficient compared with VCoSb.

Supplementary Materials: The following are available online at http://www.mdpi.com/1996-1944/12/10/1637/s1, Figure S1: The Lorentz number estimated by fitting the Seebeck coefficient, Figure S2: Temperature-dependent electrical conductivity (a), Seebeck coefficient (b), power factor (c), and XRD pattern (d) of CoSb.

Author Contributions: Conceptualization, L.H. and J.W.; Methodology, L.H.; Software, L.H.; Validation, L.H. and C.W.; Formal Analysis, L.H., Q.Z.; Investigation, J.W.; Resources, X.M. and X.L.; Data Curation, S.M.; Writing-Original Draft Preparation, L.H. and J.W.; Writing-Review \& Editing, L.H.; Supervision, L.H. and Q.Z.; Project Administration, X.M. and L.H.

Funding: The work was supported by the Young Scientist Fund of National Natural Science Foundation of China (No. 51601152), the Open Research Subject of Key Laboratory of Special Materials and Manufacturing Technology (No. SZJJ2016-034), the Open Research Subject of Key Laboratory of Fluid and Power Machinery (Xihua University), Ministry of Education (No. SZJJ2017-082), and the Sichuan Science and Technology Program (No.2019JDTD0024).

Conflicts of Interest: The authors declare no conflicts of interest.

\section{References}

1. Su, X.L.; Hao, S.Q.; Bailey, T.P.; Wang, S.; Hadar, I.; Tan, G.J.; Song, T.B.; Zhang, Q.J.; Uher, C.; Wolverton, C.; et al. Weak electron phonon coupling and deep level impurity for high thermoelectric performance $\mathrm{Pb}_{1-x} \mathrm{Ga}_{x} \mathrm{Te}$. Adv. Energy Mater. 2018, 8, 1800659. [CrossRef]

2. Tan, G.J.; Zeier, W.G.; Shi, F.Y.; Wang, P.L.; Snyder, G.J.; Dravid, V.P.; Kanatzidis, M.G. High thermoelectric performance $\mathrm{SnTe}-\mathrm{In}_{2} \mathrm{Te}_{3}$ solid solutions enabled by resonant levels and strong vacancy phonon scattering. Chem. Mater. 2015, 27, 7801-7811. [CrossRef]

3. Liu, W.; Tan, X.J.; Yin, K.; Liu, H.J.; Tang, X.F.; Shi, J.; Zhang, Q.J.; Uher, C. Convergence of conduction bands as a means of enhancing thermoelectric performance of n-type $\mathrm{Mg}_{2} \mathrm{Si}_{1-x} \mathrm{Sn}_{x}$ solid solutions. Phys. Rev. Lett. 2012, 108, 166601. [CrossRef] 
4. Pei, Y.Z.; LaLonde, A.D.; Wang, H.; Snyder, J.G. Low effective mass leading to high thermoelectric performance. Energy Environ. Sci. 2012, 5, 7963-7969. [CrossRef]

5. Shuai, J.; Mao, J.; Song, S.W.; Zhu, Q.; Sun, J.F.; Wang, Y.M.; He, R.; Zhou, J.W.; Chen, G.; Singh, D.J.; et al. Tuning the carrier scattering mechanism to effectively improve the thermoelectric properties. Energy Environ. Sci. 2017, 10, 799-807. [CrossRef]

6. Yu, J.J.; Fu, C.G.; Liu, Y.T.; Xia, K.Y.; Aydemir, U.; Chasapis, T.C.; Snyder, G.J.; Zhao, X.B.; Zhu, T.J. Unique role of refractory Ta alloying in enhancing the figure of merit of $\mathrm{NbFeSb}$ thermoelectric materials. Adv. Energy Mater. 2017, 1701313, 1-8. [CrossRef]

7. Chai, Y.W.; Oniki, T.; Kenjo, T.; Kimura, Y. The effect of an isoelectronic Ti-Zr substitution on Heusler nanoprecipitation and the thermoelectric properties of a $\left(\mathrm{Ti}_{0.2}, \mathrm{Zr}_{0.8}\right) \mathrm{Ni}_{1.1} \mathrm{Sn}$ half-Heusler alloy. J. Alloy Compd. 2016, 662, 566-577. [CrossRef]

8. Zhao, L.D.; Lo, S.H.; Zhang, Y.S.; Sun, H.; Tan, G.J.; Uher, C.; Wolverton, C.; Dravid, V.P.; Kanatzidis, M.G. Ultralow thermal conductivity and high thermoelectric figure of merit in SnSe crystals. Nature 2014, 508, 373-377. [CrossRef] [PubMed]

9. Chen, X.; Parker, D.; Singh, D.J. Importance of non-parabolic band effects in the thermoelectric properties of semiconductors. Sci. Rep. 2013, 3, 3168. [CrossRef]

10. Zhu, T.J.; Fu, C.G.; Liu, X.H.; Liu, Y.T.; Zhao, X.B. High efficiency half-Heusler thermoelectric materials for energy harvesting. Adv. Energy Mater. 2015, 5, 1500588. [CrossRef]

11. Rausch, E.; Balke, B.; Stahlhofen, J.M.; Ouardi, S.; Burkhardt, U.; Felser, C. Fine tuning of thermoelectric performance in phase-separated half-Heusler compounds. J. Mater. Chem. C 2015, 3, 10409-10414. [CrossRef]

12. Zhu, T.J.; Liu, Y.T.; Fu, C.G.; Heremans, J.P.; Snyder, J.G.; Zhao, X.B. Compromise and synergy in high-efficiency thermoelectric materials. Adv. Mater. 2017, 1605884, 1-26.

13. Zhang, H.; Wang, Y.M.; Dahal, K.; Mao, J.; Huang, L.H.; Zhang, Q.Y.; Ren, Z.F. Thermoelectric properties of n-type half-Heusler compounds $\left(\mathrm{Hf}_{0.25} \mathrm{Zr}_{0.75}\right)_{1-x} \mathrm{Nb}_{x} \mathrm{NiSn}$. Acta Mater. 2016, 113, 41-47. [CrossRef]

14. He, R.; Huang, L.H.; Wang, Y.M.; Samsonidze, G.; Kozinsky, B.; Zhang, Q.Y.; Ren, Z.F. Enhanced thermoelectric properties of n-type NbCoSn half-Heusler by improving phase purity. Appl. Mater. 2016, 4, 104804. [CrossRef]

15. Fu, C.G.; Zhu, T.J.; Liu, Y.T.; Xie, H.H.; Zhao, X.B. Band engineering of high performance p-type FeNbSb based half-Heusler thermoelectric materials for figure of merit ZT > 1. Energy Environ. Sci. 2015, 8, $216-220$. [CrossRef]

16. Liu, W.S.; Kim, H.S.; Chen, S.; Jie, Q.; Lv, B.; Yao, M.L.; Ren, Z.S.; Opeil, C.P.; Wilson, S.; Chu, C.W.; et al. $\mathrm{N}$-type thermoelectric material $\mathrm{Mg}_{2} \mathrm{Sn}_{0.75} \mathrm{Ge}_{0.25}$ for high power generation. PNAS 2015, 112, 3269. [CrossRef] [PubMed]

17. Chen, L.; Liu, Y.M.; He, J.; Tritt, T.M.; Poon, S.J. High thermoelectric figure of merit by resonant dopant in half-Heusler alloys. AIP Adv. 2017, 7, 065208. [CrossRef]

18. Silpawilawan, W.; Kurosaki, K.; Ohishi, Y.; Muta, H.; Yamanaka, S. FeNbSb p-type half-Heusler compound: Beneficial thermomechanical properties and high-temperature stability for thermoelectrics. J. Mater. Chem. C 2017, 5, 6677-6681. [CrossRef]

19. Fu, C.G.; Bai, S.Q.; Liu, Y.T.; Tang, Y.S.; Chen, L.D.; Zhao, X.B.; Zhu, T.J. Realizing high figure of merit in heavy-band $p$-type half-Heusler thermoelectric materials. Nat. Commun. 2015, 6, 8144-8150. [CrossRef] [PubMed]

20. Zhao, D.G.; Zuo, M.; Bo, L.; Wang, Y.P. Synthesis and thermoelectric properties of Pb-Doped ZrCoBi Half-heusler compounds. Materials 2018, 11, 728. [CrossRef]

21. Yan, Y.G.; Geng, W.Q.; Qiu, J.H.; Ke, H.Q.; Luo, C.; Yang, J.H.; Uher, C.; Tang, X.F. Thermoelectric properties of n-type ZrNiSn prepared by rapid non-equilibrium laser processing. RSC Adv. 2018, 8, 15796-15803. [CrossRef]

22. Dow, H.; Kim, W.; Shin, W.G. Effect of $\mathrm{C}$ and $\mathrm{N}$ addition on thermoelectric properties of TiNiSn half-Heusler compounds. Materials 2018, 11, 262. [CrossRef]

23. Huang, L.H.; He, R.; Chen, S.; Zhang, H.; Dahal, K.S.; Zhou, H.Q.; Wang, H.; Zhang, Q.Y.; Ren, Z.F. A new n-type half-Heusler thermoelectric material NbCoSb. Mater. Res. Bull. 2015, 70, 773-778. [CrossRef]

24. Zhang, H.; Wang, Y.; Huang, L.; Chen, S.; Dahal, H.; Wang, D.; Ren, Z. Synthesis and thermoelectric properties of n-type half-Heusler compound VCoSb with valence electron count of 19. J. Alloy Compd. 2016, 654, 321-326. [CrossRef] 
25. Huang, L.H.; Wang, Y.M.; Shuai, J.; Zhang, H.; Yang, S.Q.; Zhang, Q.Y.; Ren, Z.F. Thermal conductivity reduction by isoelectronic elements $\mathrm{V}$ and $\mathrm{Ta}$ for partial substitution of $\mathrm{Nb}$ in half-Heusler $\mathrm{Nb}_{(1-x) / 2} \mathrm{~V}_{(1-x) / 2} \mathrm{Ta}_{x} \operatorname{CoSb}$. RSC Adv. 2015, 5, 102469-102476. [CrossRef]

26. Huang, L.H.; Zhang, Q.Y.; Wang, Y.M.; He, R.; Shuai, J.; Zhang, J.J.; Wang, C.; Ren, Z.F. The effect of Sn doping on thermoelectric performance of n-type half-Heusler NbCoSb. Phys. Chem. Chem. Phys. 2017, 19, 25683-25690. [CrossRef]

27. Huang, L.H.; Wang, J.C.; Chen, X.; He, R.; Shuai, J.; Zhang, J.J.; Zhang, Q.Y.; Ren, Z.F. The effects of excess Co on the phase composition and thermoelectric properties of half-Heusler NbCoSb. Materials 2018, 11, 773. [CrossRef]

28. Zeier, W.G.; Anand, S.; Huang, L.; He, R.; Zhang, H.; Ren, Z.; Wolverton, C.; Snyder, G.J. Using the 18-electron rule to understand the nominal 19-electron half-Heusler $\mathrm{NbCoSb}$ with $\mathrm{Nb}$ vacancies. Chem. Mater. 2017, 29, 1210-1217. [CrossRef]

29. Xia, K.Y.; Liu, Y.T.; Anand, S.; Snyder, G.J.; Xin, J.Z.; Yu, J.J.; Zhao, X.B.; Zhu, T.J. Enhanced thermoelectric performance in 18-electron $\mathrm{Nb}_{0.8}$ CoSb half-Heusler compound with intrinsic $\mathrm{Nb}$ vacancies. Adv. Funct. Mater. 2018, 28, 1705845. [CrossRef]

30. Ibanez, M.; Luo, Z.S.; Genc, A.; Piveteau, L.; Ortega, S.; Cadavid, D.; Dobrozhan, O.; Liu, Y.; Nachtegaal, M.; Zebarjadi, M.; et al. High-performance thermoelectric nanocomposites from nanocrystal building blocks. Nat. Commun. 2016, 7, 10766. [CrossRef]

31. Xie, H.H.; Wang, H.; Pei, Y.Z.; Fu, C.G.; Liu, X.H.; Snyder, G.J.; Zhao, X.B.; Zhu, T.J. Beneficial contribution of alloy disorder to electron and phonon transport in half-Heusler thermoelectric materials. Adv. Funct. Mater. 2013, 23, 5123-5130. [CrossRef]

32. Fu, C.G.; Zhu, T.J.; Pei, Y.Z.; Xie, H.H.; Wang, H.; Snyder, G.J.; Liu, Y.; Liu, Y.T.; Zhao, X.B. High band degeneracy contributes to high thermoelectric performance in p-type half-Heusler compounds. Adv. Energy Mater. 2014, 4, 1400600. [CrossRef]

33. Li, J.H.; Tan, Q.; Li, J.F.; Liu, D.W.; Li, F.; Li, Z.Y.; Zou, M.M.; Wang, K. BiSbTe-based nanocomposites with high ZT: The effect of SiC nano dispersion on thermoelectric properties. Adv. Funct. Mater. 2013, 23, 4317-4323. [CrossRef]

34. Jiang, Q.H.; Yang, J.Y.; Xin, J.W.; Zhou, Z.W.; Zhang, D.; Yan, H.X. Carriers concentration tailoring and phonon scattering from n-type zinc oxide $(\mathrm{ZnO})$ nanoinclusion in $\mathrm{p}$ - and n-type bismuth telluride $\left(\mathrm{Bi}_{2} \mathrm{Te}_{3}\right)$ : Leading to ultralow thermal conductivity and excellent thermoelectric properties. J. Alloy Compd. 2017, 694, 864-868. [CrossRef]

(C) 2019 by the authors. Licensee MDPI, Basel, Switzerland. This article is an open access article distributed under the terms and conditions of the Creative Commons Attribution (CC BY) license (http://creativecommons.org/licenses/by/4.0/). 